\title{
Where the world ended: re-unification and identity in the german borderland*
}

Em 1991, um ano depois de estar em campo, no vilarejo de Kella, a antropóloga norte-americana Daphne Berdahl observou que várias mulheres do local começaram a se reunir para pintar tecidos juntas. Essa observação não era banal. Para além de ser um modo de se manterem ocupadas, tais mulheres estavam tentando renovar uma comunidade que se perdeu quando a fábrica na qual elas trabalhavam foi fechada. A autora logo viu que deveria haver um sentido nessa produção coletiva; com isso, viu também que elas estavam re-criando uma memória do socialismo e, ainda, um modo de se distinguir das mulheres da Alemanha Ocidental.

Todavia, para mostrarmos a importância desses encontros aparentemente comuns, é preciso antes dizer onde está Kella, bem como os temas e propósitos do livro de Berdahl.

Era em Kella que se localizava a separação entre a Alemanha Oriental e a Ocidental. Ali estava a fronteira que dividia o Leste do Oeste, o capitalismo do socialismo, e a própria Kella de um mero contato com o resto do mundo. Com a construção do "Muro de Berlim", Kella acabou se tornando, para seus moradores, "o lugar onde o mundo terminava": apenas uma única rodovia ligava a vila ao restante da Alemanha Oriental $e$

\footnotetext{
* Resenha de BERDAHL, Daphne. Where the world ended: re-unification and identity in the german borderland. Berkeley and Los Angeles, University of California Press, 1999. Recebida para publicação em fevereiro de 2009, aceita em maio de 2009.

** Doutoranda em Antropologia, Instituto de Filosofia e Ciências Humanas, Unicamp.tanielerui@yahoo.com.br
}

cadernos pagu (32), janeiro-junho de 2009:411-418. 
Where the world ended

seus seiscentos habitantes precisavam de licença para sair e para entrar na cidade. Duzentos anos antes, essa mesma linha fronteiriça delineava não somente o Leste do Oeste, mas também Prússia e Hesse, Thuringia e Hesse, Católicos e Protestantes. Kella era, assim, uma vila de muitas fronteiras, de fronteiras literais $e$ metafóricas, todas elas faziam parte de uma narrativa de identificação local. Kella era também um lugar para construir e articular identidades e distinções, bem como, uma zona de interstício cultural. Por causa de sua história de fronteira, o Estado em Kella era uma presença constante e visível; algo que, no dia-adia, as pessoas tinham que interpretar, sobretudo porque fronteiras geram estórias, lendas, eventos e incidentes; são contestadas e negociadas de formas específicas, tanto pelos indivíduos quanto pelo Estado.

Fruto de um trabalho de campo de dois anos (1990-1992) em um lugar tão sui generis, o texto de Berdahl é tanto um relato etnográfico da reunificação da Alemanha, quanto uma tentativa de entender a condição paradoxal da fronteira - que é, a um só tempo, a metáfora que organiza o livro e o seu objeto de estudo. Desse modo, Where the world ended é um livro sobre fronteiras, limites e todos os espaços entre eles. Numa afirmativa apressada,

é sobre como limites geográficos podem ser investidos com significados culturais, para além das intenções políticas, $e$ sobre como seu desmantelamento pode tanto desestabilizar quanto gerar novas práticas e identidades culturais (1).

Decorre dessa afirmativa que a principal questão perseguida é o que acontece ao sentido de identidade e personalidade das pessoas quando elas passam por um colapso no sistema político $e$ econômico e, ainda, como as pessoas negociam e manipulam uma condição liminar criada pelo desaparecimento de um significativo quadro de referência. Mas o livro é mais que isso: Berdhal busca discutir essa problemática à luz de vários aspectos da vida social, entre eles identidade nacional, memória, gênero, 
religião e consumo. E é melhor ainda porque ela não vê tais aspectos como categorias separadas, mas como sendo eles também "zonas de fronteiras sobrepostas e frequentemente interdependentes, que cruzam a vida cotidiana das pessoas" (19). Tomados juntos, tais aspectos não somente ilustram continuidades importantes entre socialismos e pós-socialismos, mas também iluminam os múltiplos modos nos quais o Estado-Nação tenta implantar a si mesmo no dia-a-dia dos indivíduos.

Embora dedique parte do livro a uma história local (e do local), este ganha em descrições e análises quando ela relata as transformações materiais e simbólicas - algumas dramáticas, outras divertidas - que marcaram a vida dos habitantes de Kella com a queda do Muro. Junto com os novos significados do consumo (em que tudo o que era do Oeste passou a ser considerado melhor simplesmente porque não era do Leste), práticas de identidade e construção de alteridade começam a aparecer de ambos os lados da fronteira. Taxonomias de classificação e de identificação de quem é "Ossi" e de quem é "Wessi" se tornam parte do cotidiano. Para além de identificar, respectivamente, os alemães oriundos do Leste e os oriundos do Oeste, essa classificação carrega uma hierarquia e "Ossi" passa a ser um atributo pejorativo.

O mais interessante é que tal classificação é feita, sobretudo, através da leitura dos corpos. "Ossis" eram identificados pela face pálida, cabelos oleosos, pobre tratamento dental, jeans surrados, sapatos genéricos, perfumes baratos. Ao passo que os "Wessi" eram conhecidos por seus cortes de cabelo "estilosos", sapatos Gucci, bolsas ecologicamente corretas e por serem mais seguros e arrogantes. A falta de certa fluência cultural no consumo emergiu como marca chave de um "Ossi", pois ele sempre andava de cabeça baixa e perguntava ao vendedor não onde estava tal produto, mas se o tinha - pergunta fruto de uma economia onde os bens eram escassos. "Ossis" eram sempre vistos como ignorantes em matéria de consumo e tal ignorância era sempre ridicularizada e explorada. Adquirir certa "competência cultural" 
Where the world ended

no consumo se tornava, assim, um rito de iniciação no interior de uma nova sociedade. Tais marcas de distinções desapareciam à medida que "Ossis" tentavam copiar o estilo de vida dos ocidentais.

Se alguns "Ossis" tentavam adquirir a tal "competência cultural" no consumo, outros, entretanto, tentavam resistir paradoxo esse que, segundo a antropóloga, reflete os aspectos contraditórios e complexos da identidade na fronteira. Muitas mulheres de Kella voltaram a usar roupas que não eram consideradas "modernas" no Ocidente e a usar detergentes do Leste. Famílias voltaram a usar seus carros antigos. Homens voltaram a consumir cervejas da Alemanha Oriental. Em poucos anos, práticas sutis de resistência simbólica se tornaram práticas culturais disseminadas pela Alemanha Oriental num fenômeno que foi chamado de "renascimento da GDR".

É nesse aspecto e nesse contexto que o fato de as mulheres de Kella se reunirem para pintar juntas passa a ter importância central, uma vez que a recriação de um espaço feminino era capaz de promover a discussão entre a experiência delas em contraste com a experiência das mulheres ocidentais. Esse acontecimento revelador capturou o peso da consciência social dessas mulheres, que estavam recriando para elas mesmas, por um breve momento, o espaço feminino que foi perdido com o fechamento das fábricas. Mas o que de fato foi perdido? Para responder a essa pergunta, é preciso retomar a experiência dessas mulheres sob o socialismo.

Durante o período socialista, mulheres negociaram contradições que estavam presentes na própria ideologia de gênero do Estado: a proclamação da igualdade de gênero, de um lado, e a política pró-natalista que incentivava papéis tradicionais da mulher, de outro. Em Kella, a ideologia da igualdade de gênero também entrava em conflito com a forte presença da Igreja Católica e sua tradicional visão sobre a mulher, que reforçava sua responsabilidade pela esfera doméstica. Com a reunificação, essa visão tradicional foi ainda desafiada por um diferente conjunto de 
ideologias de gênero que competiam com as idéias feministas ocidentais. Nesse sentido, diz Berdahl, "gênero pode ser visto como um jogo dinâmico entre internacionalização, negociação $e$ contestação de diversas e competitivas ideologias de gênero" (193).

Como em toda a Alemanha Oriental, a força de trabalho em Kella foi rigidamente segregada por gênero durante o socialismo 99\% das mulheres trabalhavam fora de casa e mais da metade em fábricas mantidas pelo Estado, exclusivamente para empregar mulheres. Além de ser um lugar de emprego, essas fábricas eram lugares de encontro e de disseminação de "fofocas", conhecimentos e trocas de informação. Também eram locais onde o Estado promovia sua ideologia para as "mães-trabalhadoras". Mesmo as creches e os consultórios médicos ficavam localizados nas fábricas.

A Constituição da Alemanha Oriental assegurava não somente igualdade legal, mas de pagamento para trabalho igual. Toda mulher grávida tinha garantido um ano de salário depois do nascimento da criança e, desde 1972, havia direito ao aborto durante o primeiro trimestre da gravidez. Participação na esfera política era também parte dos direitos, privilégios e obrigações das mulheres sob o socialismo. O esforço do Estado de integrar as mulheres nos trabalhos do Partido envolveu-as em uma variedade de funções políticas: por um sistema de cotas, $30 \%$ dos membros do conselho da vila deveriam ser mulheres.

Como as revistas femininas socialistas indicam, era esperado que as mulheres combinassem maternidade, serviço doméstico, ativismo político e trabalho assalariado. A sua identidade de trabalhadoras e mães também servia para reforçar o papel "natural" da mulher: geradoras da nação socialista $e$ socializadoras dos seus cidadãos. O esforço para atender a tudo isso afetava a vida das mulheres de maneira muito pessoal.

Dezoito meses depois da queda do muro, as fábricas socialistas fecharam. Com poucas perspectivas de emprego, especialmente para mulheres que tinham mais de 40 anos, a 
Where the world ended

maioria foi relegada à esfera doméstica e se tornou "dona-decasa" pela primeira vez em suas vidas. Sem emprego, perdiam também as informações e os eventos que ocorriam na vila. Muitas se viram isoladas. Parando de se ver, o sentimento de futilidade $e$ a insegurança financeira, além da perda de uma identidade trabalhadora, contribuíram para que muitas entrassem em depressão. A participação das mulheres na política também caiu muito com o fim das cotas. Todas essas transformações ocasionaram a revalorização e reorganização das relações familiares. O tempo e o espaço dessas mulheres também tiveram que ser transformados.

Uma forma que a antropóloga encontrou para analisar a tensão produzida pelas contrastantes ideologias de feminilidade e os sentimentos de inferioridade $e$ inutilidade relatados por essas mulheres foi explorar ainda mais a tensão entre Leste e Oeste, $e$ mostrar como também essa tensão pode ser diferentemente estruturada, vivenciada e rememorada em termos de gênero. Pois na distinção que lia os corpos "ossis" e "wessis", lia-se, principalmente, o corpo feminino, onde as diferenças eram vistas mais imediatamente, especialmente nas mulheres mais velhas e de meia-idade, que podiam ser identificadas pelas suas próprias roupas, maquiagem, cabelos, acessórios, cuidados com os dentes e/ou com a pele. Em um esforço para se "misturar", muitas mulheres descartaram suas roupas, mudaram seus cabelos $e$ gastaram muito para terem produtos "ocidentais" em suas casas. Outras, entretanto, resistiram - o que contribui para não termos uma visão homogênea das mulheres na Alemanha Oriental.

Essas que resistiram foram ainda além da simples recusa a não assumir um corpo "wessi". Elas se reapropriaram de uma identidade socialista de "worker-mothers" como um símbolo de distinção entre elas e as mulheres da Alemanha Ocidental. É verdade que construíram essa identidade a partir de estereótipos imaginados, sobretudo pela idéia que tinham das mulheres donasde-casa das décadas de 1960 e 1970; mas isso também reflete as tensões que têm sido, e continuam sendo, negociadas $e$ 
Taniele Rui

contestadas de muitos modos, tanto individuais quanto coletivamente.

O mais interessante disso é que um ano depois do silêncio que seguiu à queda do Muro, em que não houve nenhuma menção sobre as vantagens do sistema socialista, foram essas mulheres as primeiras na vila a iniciar a discussão sobre os aspectos positivos da vida sob o socialismo, demonstrando como a memória histórica e a identidade nacional podem ser fenômenos de interação complexos marcados por gênero.

Ao fazer tal afirmação, Berdahl nos faz pensar sobre os paradoxos e contradições presentes nas fronteiras, sobre o modo como esses paradoxos podem ser diferentemente vividos $e$ experenciados em termos de gênero, e sobre o modo como as fronteiras políticas e culturais marcam profundamente o dia-a-dia das pessoas, suas redes de relações e a visão que fazem de si. $\mathrm{O}$ mérito do trabalho é fazer tudo isso a partir de uma conexão quase perfeita entre descrição $e$ análise. Isso porque mostrar a realidade das fronteiras envolve mostrar como esta afeta as várias esferas que compõem a vida social. Envolve mostrar também os distintos arranjos e negociações feitos diariamente pelos indivíduos, não como estratégias de resistência ou tentativa de assimilação, mas como frutos da própria condição de viver na fronteira.

Quase perfeita, porque acredito que o escorregão da antropóloga é ver as identidades tensas e conflituosas de "Ossis" e "Wessis" como frutos de uma fronteira cultural que emergiu com o fim de uma fronteira política. Segundo ela, a Alemanha pode até ser unificada em um Estado, mas seus cidadãos teriam permanecido dois povos separados culturalmente. E seria essa diferença cultural que teria produzido as tensões resultantes da abertura da fronteira. Seria essa diferença cultural que teria feito, por exemplo, algumas mulheres recusarem a ideologia de gênero ocidental $e$ voltarem a valorizar a identidade de mães $e$ trabalhadoras que tinham sob o socialismo. Penso que não está na diferença cultural a grande chave explicativa para essa tensão. 
Where the world ended

Concordando com outro dos seus argumentos, penso ser melhor afirmar que se trata de mais uma das tantas formas que as pessoas encontram para interpretar, negociar, contestar $e$ incorporar processos sociais, políticos e econômicos que ocorrem num nível extra-local. Nesse sentido, a distinção tensa e conflituosa entre Leste e Oeste faz parte da própria dinâmica de manutenção $e$ invenção das fronteiras. E o maior ensinamento da vida nas fronteiras é mostrar como seus efeitos no dia-a-dia das pessoas são sempre reais. Como Glória Anzaldúa escreveu, em citação que a própria Berdhal recuperou, a fronteira é "um lugar vago $e$ indeterminado pelos resíduos emocionais e limites não naturais". Acho que, neste caso, não é apenas de diferenças culturais que estamos falando.

Levando em conta essa crítica, que em nada invalida a reflexão analítica promovida pelo livro, Where the World ended é um convite à reflexão sobre as separações, tensões e contatos daqueles que vivem na condição limiar das fronteiras. No caso específico da contribuição aos estudos de gênero, é um convite a pensar gênero junto com as tantas outras esferas da vida social e a pensar como a memória nacional, quando vista à luz das experiências de gênero, pode complexificar ainda mais a imagem que temos de um determinado sistema político. 